from field observations. Such explanations would have increased the volume's scientific impact. This omission reflects some reticence of Arctic countries to divulge detailed geo-referenced data about their soils and forestry to their neighbours. Now that climate researchers are, quite rightly, under pressure to be transparent about their source data and models, inventory agencies in each country should follow suit. It is a step in the right direction that the Soil Atlas maps are openly accessible online (see go.nature.com/TaMdZR).

Knowledge of the northern soils could benefit many disciplines, from studies of landscape formation to meteorology, climatology, ecology, biogeochemistry and hydrology. To allow further analyses, these data will need to be translated into a form that is amenable to computer modelling - for instance, tabulated soil depths, hydraulic properties, conductivity, and carbon and nutrient content. This can be done if researchers combine their efforts, so let's hope that the collaborative spirit of the International Polar Year lives on.

Philippe Ciais is a researcher at the French Atomic Energy and Alternative Energies Commission (CEA) and associate director of the Laboratory of Climate and Environmental Sciences, Gif sur Yvette, France.

e-mail:philippe.ciais@cea.fr

\title{
On markets and collective mood
}

\author{
Mood Matters: From Rising Skirt Lengths to \\ the Collapse of World Powers \\ by John L. Casti \\ Springer: 2010.210 pp. $\$ 27.50$
}

Elections, markets and judicial systems rest on the presumption that people make conscious, logical choices based on stable preferences. Journals are packed with evidence to the contrary. Among the variables recently suggested to affect important decisions are rain, hunger, sexual arousal and the colour of ink used to express one's views.

With reason dethroned as the ruling explanation for people's conduct, the search is on for another framework in which human behaviour can be modelled. In Mood Matters, complexity mathematician John Casti argues that collective psychology is the place to look. The irrationality that matters - leading to financial panics, terrorist acts and political lurches - is not within individuals but among them, he says. Moreover, Casti believes that major social changes are signalled by fluctuations in markets. Reflecting the collective mood, financial data are reservoirs of social information that can be tapped to predict crises.

Mood Matters is a brief for the field of socionomics, a term coined by stock-market analyst Robert R. Prechter in the 1980s. It describes a nascent discipline that, Casti says, will explain and predict social change using reliable laws of human nature. Its instrument is stock-market indices, records of the prices of precious metals and the like. Because they have been recorded in detail for more than a century, financial markets are arguably one of the best measures of the attitudes of populations. The data are "clean", Casti notes, and there are abundant tools for analysing them.

Casti follows Prechter in arguing that social mood - defined as a group's collective belief about the future - is the main driver of wars, political upheavals, terrorist campaigns, changes in fashion and economic booms and busts. Since 1700 , he writes, major wars have tended to follow drops in stock prices. He discerns two types of collective mood: pessimistic and optimistic. Each mood moves through society in two phases so that nations, regions and even the whole world travel on an endless oscillation of mass emotion. Optimism, experienced first as hope then hubris, is followed by pessimism, felt as fear then despair, over many timescales. Returning to optimism once more, the cycle repeats.

What causes social moods to form? Quoting Prechter, Casti offers only the thin notion that all people have an "impulse to herd in contexts of uncertainty". This will not satisfy social scientists. Similarly hazy is the book's definition of the group that shares this mass emotion. Casti assigns a single mood at a given time to a particular collective, whether that is the population of a city, country or even the world. But each of us belongs to more than one social group, so how can we have one belief about the

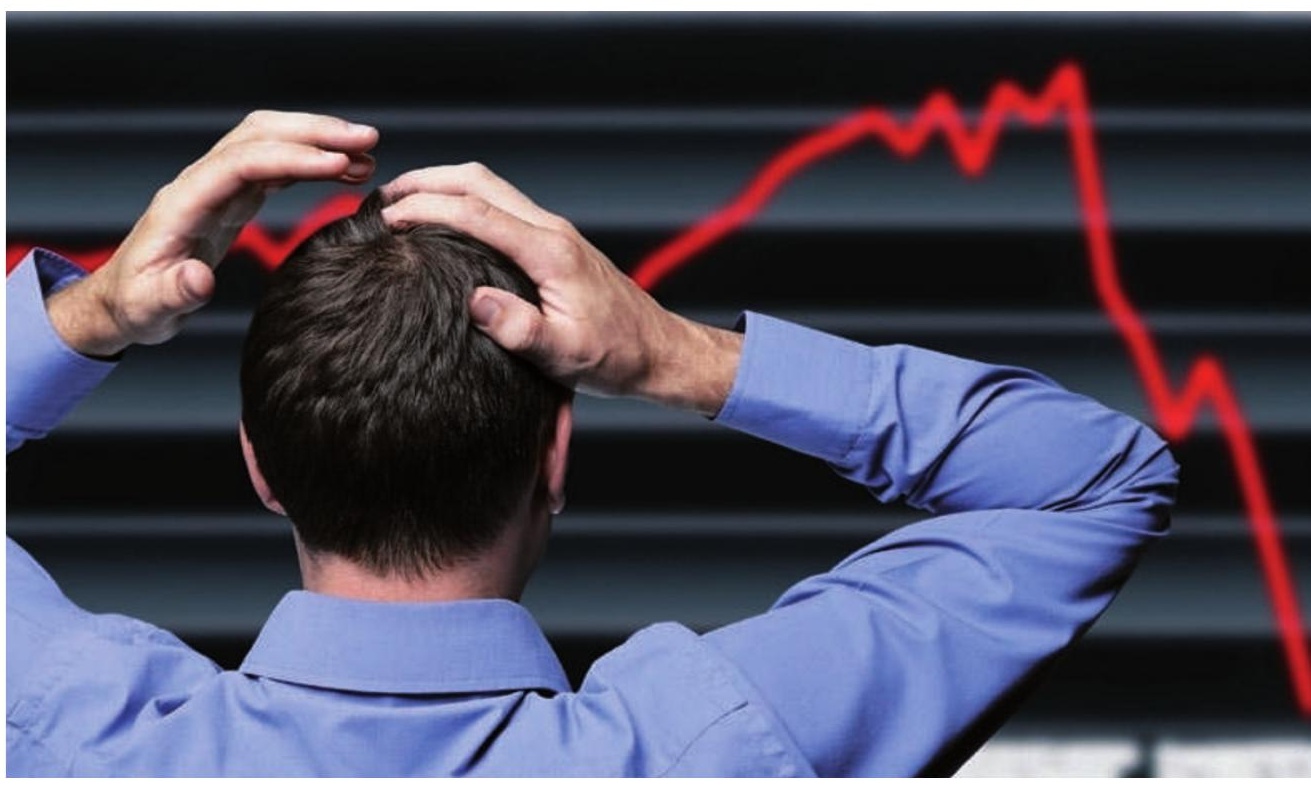

Collective psychology might be mirrored in the social information contained in financial market indices. future? How do individual beliefs contribute to the shared mood? How are variations over time to be reckoned with? All questions for the future, Casti says.

With so many key concepts left undefined, Mood Matters offers only trends and examples - horror movies are popular after stock prices have fallen, and incumbent politicians are not. This is not the "plausible chain of connection" that Casti hopes will make a scientific law distinct from a mere correlation. Similarly baseless are the inferences he draws between precise numbers and vague social concepts for instance, between the Dow Jones Industrial Average and pessimism.

Casti is right to ask how we should move to a post-rational model of human nature, but he does not make the case that market data trends are the road to insight. There is no short cut around the lab through the stock-market tables.

David Berreby writes the Mind Matters blog on BigThink.com and is the author of Us and Them: The Science of Identity.

e-mail: david@davidberreby.com 